\title{
A ELEVAÇÃO DO ESPÍRITO PENSSANTE A DEUSS, OU A NATUREZA LÓGICA DO CONCEITO NAS PRELEÇÕES DE HEGEL SOBRE AS PROVAS DA EXISTÊNCIA DE DEUS
}

\section{THE ELEVATION OF THE THINKING SPIRIT TOWARDS GOD OR THE LOGICAL NATURE OF THE CONCEPT IN HEGEL'S LECTURES ON THE PROOF OF GOD'S EXISTENCE}

Marco Aurélio Werle*

\begin{abstract}
RESUMO - O artigo investiga a relação existente na filosofia de Hegel entre as provas sobre a existência de Deus e a elevação do espírito humano a Deus. Dois pontos serão ressaltados: a apreensão de Deus como espírito e a natureza lógica do Conceito e isso a partir do modo como Hegel discute tanto a necessidade histórica da "prova" da existência de Deus, surgida com o Cristianismo, quanto o sentido lógico-especulativo das duas principais modalidades dessas provas: a prova ontológica e a prova cosmológica.

PALAVRAS-CHAVE - Hegel. Deus. Lógica. Espírito. Idealismo alemão.

ABSTRACT - The article investigates the existing relations in Hegel's philosophy between the proofs of God's existence and the human spirit elevation toward God. Two points will be highlighted: the understanding of God as spirit and the logic nature of the Concept from the way Hegel discusses both, the historical necessity of the "proofs" of God's existence, emerged with the Christianism and the logic-especulative sense of the two main modalities of these proofs: the ontological proof and the cosmological proof.

KEYWORDS - Hegel. God. Logic. Spirit. German idealism.
\end{abstract}

"A relação entre si das determinações de Deus é um assunto muito difícil por si mesmo, e mais ainda para aqueles que não conhecem a natureza do conceito. Sem pelo menos conhecer algo do conceito do conceito, sem ter dele ao menos uma representação, não se pode compreender nada da essência de Deus como espírito em geral."

HEGEL, 1986c, p. 399.

* Professor Associado livre-docente na USP. Pesquisador nível II do CNPq. E-mail: <mawerle@usp.br>.

\begin{tabular}{|l|l|l|l|l|l|}
\hline Veritas & Porto Alegre & v. 55 & n. 3 & set./dez. 2010 & p. 178-185 \\
\hline
\end{tabular}


Na abertura das Preleções sobre as provas da existência de Deus, do ano de 1829, Hegel informa aos seus ouvintes que as preleções que se seguem possuem uma conexão com a preleção sobre lógica, que ele estava então ministrando no mesmo semestre. Mais precisamente, aquelas seriam uma "espécie de acréscimo a essa, não segundo o conteúdo, mas segundo a forma, uma vez que o objeto [das mesmas] é apenas uma figura peculiar das determinações fundamentais da lógica" (HEGEL, 1986c, p. 347).

Em princípio, não parece surpreendente essa associação entre as provas da existência de Deus com o âmbito da lógica, já que a lógica, como se sabe, ocupa-se justamente com o que vem a ser uma prova. Dessa forma, torna-se necessário apelar a essa ciência para que se possa saber sob que condições é possível ou não provar a existência de Deus, que, como também se sabe, não é um assunto que se deixa provar facilmente, haja vista as inúmeras provas da existência de Deus fornecidas ao longo da história da filosofia. Poder-se-ia então imaginar que Hegel irá, nas preleções sobre a prova da existência de Deus, explorar um caso exemplar da aplicação da ciência da lógica, isto é, irá explicitar logicamente, digase dialeticamente, como se apresenta esse objeto.

Entretanto, logo a seguir Hegel indica que o caráter lógico aqui envolvido "não constitui meramente o lado formal, mas encontra-se efetivamente no centro do conteúdo da filosofia da religião" (HEGEL, 1986c, p. 347). Ou seja, a relação da lógica com as provas da existência de Deus não concerne somente ao fato de que a lógica é um meio pelo qual se examina a correção da prova, no sentido de que é a ciência das regras corretas de pensar. Pelo contrário, o que Hegel nos dá a entender é que o tema "Deus" nos fornece uma oportunidade para repensarmos ou aprofundarmos o conteúdo da própria lógica, bem como somente se pode colocar em questão e compreender o assunto da prova da existência de Deus se partirmos da lógica, a saber, não apenas a tomarmos como algo externo, como instrumento de pensamento, mas como sendo a própria apresentação do absoluto e de Deus.

Diante disso, nada mais equivocado do que imaginar que Hegel, nessas preleções, está empenhado em tentar provar, pela enésima vez, a existência de Deus e, por conseguinte, encontra-se envolvido com um assunto ultrapassado. Igualmente é errôneo supor que Hegel esteja "alienado do real", mais precisamente, em descompasso com o momento histórico imediatamente anterior à Revolução de Julho na França ${ }^{1}$ e do

1 Revolta da população de Paris, entre os dias 27 e 29 de julho de 1830, contra a tentativa do rei Carlos X de revogar partes importantes da Carta Constitucional de 1814, o que significava a limitação do direito de voto, a dissolução da câmara e a supressão da 
que, logo a seguir, ficou conhecido como sendo o período do Vormärz [pré-março] ${ }^{2}$.

Essa é precisamente a insinuação que podemos depreender de uma observação feita por Goethe na época e que, sob certo aspecto, foi depois retomada de vários modos pela tradição marxista de pensamento. Eckermann nos relata, numa conversa que teve com Goethe em primeiro de setembro de 1829, ter feito menção "a Goethe de um viajante que passou por aqui [em Weimar] e disse estar ouvindo um curso de Hegel [em Berlim] sobre as provas da existência de Deus. Goethe me respondeu que tais preleções estão fora de época" (GOETHE, 1976, p. 370).

Para Goethe, nesse momento histórico do fim dos anos 20 do século XIX, acabou-se a época em que se tinham ainda dúvidas [Zweifel] sobre questões acerca da natureza de Deus, da separação entre a alma e o corpo e da imortalidade da alma. E quem mais teria contribuído para dissipar esses falsos dilemas teria sido Kant, quando nos mostrou os limites daquilo que o homem pode saber nesse domínio, tanto é que Kant mesmo teria abandonado esses temas à sua sorte. Por outro lado, Goethe dá a entender que atuais seriam precisamente os problemas da vida prática, por exemplo, a atuação política e comercial dos ingleses pelo globo terrestre. "Enquanto os alemães se martirizam com a solução de problemas filosóficos, os ingleses, com seu grande entendimento prático, riem de nós e conquistam o mundo" (GOETHE, 1976, p. 371). Na sequência dessa conversa com Eckermann, Goethe ainda comenta a posição dos ingleses diante da abolição da escravatura, de que, por trás dos inúmeros discursos que proferiram em favor dos direitos humanos, nada mais estaria do que a defesa de interesses imperialistas na costa africana, como bem teria notado um português no Congresso de Viena. Isto é, para os ingleses, muito mais do que ferir a moral, a escravidão lhes era prejudicial em termos comerciais, uma vez que os negros lhes eram muito mais úteis ficando na África do que sendo deportados para a América.

Certamente ou felizmente as preleções de Hegel são extemporâneas comparadas a tais fatos e "procedimentos" da vida prática. Entretanto, como já dissemos, antes de imaginar que importa ratificar ou requentar um conteúdo do passado, deve-se notar que essas preleções aprofundam

liberdade de imprensa. Carlos $\mathrm{X}$ foi deposto e como sucessor foi eleito, pela grande burguesia, o duque Luís Felipe de Orléans, chamado, por isso, de "rei burguês". Vale destacar que a Revolução de Julho desencadeou levantes e aspirações constitucionais em muitas nações europeias e impulsionou o liberalismo nascente.

2 Vormärz refere-se ao período entre 1815 e a revolução de março de 1848/49, marcado na Alemanha por conflitos idênticos aos que ocorreram na Revolução de Julho na França. 
importantes aspectos do pensamento especulativo, esse mesmo pensamento especulativo e dialético que serviu de base para Marx deslindar o mecanismo implícito da lógica de atuação comercial e econômica no início da era industrial moderna ${ }^{3}$.

Por outro lado, no § 163 da Enciclopédia das Ciências Filosóficas, Hegel nos indica que o tema da escravidão, ao qual alude Goethe em sua conversa com Eckermann, não é um assunto separado do tema de Deus. Certamente, diriam alguns, pois é sabido que as instituições cristãs, principalmente as católicas, se não apoiaram historicamente a política escravagista, ao menos estiveram silenciosamente de acordo com a mesma. Para Hegel, porém, não é dessa pequena política de que se trata, e sim há de se pensar o tema tal como se pôs em termos filosóficos e não empíricos.

Talvez seja interessante, inclusive para o propósito de nosso artigo, referir brevemente esse $§ 163$ da Enciclopédia das Ciências Filosóficas, cujo assunto não é outro senão o do "conceito como tal", para iluminar mais profundamente, a saber, especulativamente, a íntima conexão existente entre lógica, Deus e a vida prática. Hegel trata, nesse parágrafo, da natureza do conceito [Begriff] e considera que o universal [das Allgemeine], enquanto momento do conceito, é um pensamento que levou séculos até penetrar na consciência dos homens; ou seja, não é um pensamento que sempre esteve diante de nós, por assim dizer, dado "naturalmente". Foi com o Cristianismo que o universal (como categoria lógica e prática, o que vem a dar no mesmo em Hegel) encontrou seu reconhecimento pleno. Os gregos, mesmo tendo uma elevada formação cultural, não chegaram ao reconhecimento de Deus em sua verdadeira universalidade, bem como não reconheceram o homem como tal, em seu valor infinito, em sua legitimidade infinita e liberdade. Isso explica a aceitação da escravidão entre os gregos, o que, no mundo cristão, não se sustentou por muito tempo, de modo que Hegel diz: "O verdadeiro fundamento do motivo pelo qual na Europa cristã não existem mais escravos, tem de ser procurado em nada mais nada menos do que no princípio do Cristianismo. A religião cristã é a religião da liberdade absoluta e apenas para os cristãos o homem vale como tal, em sua infinitude e universalidade. O que falta ao escravo é o reconhecimento de sua personalidade; mas o princípio da personalidade é a universalidade. $O$

3 A propósito dos interesses que passaram a dominar a filosofia dessa época, que muitas vezes se toma como sendo o período do declínio do idealismo e da emergência do materialismo, Walter Jaeschke, opondo-se a uma ideia disseminada por Karl Löwith, no clássico livro De Hegel a Nietzsche, considera que "a filosofia do pré-março (no sentido de um conceito de época) é apenas em pequena escala uma filosofia do 'pré-março' (no sentido qualitativo)" (JAESCHKE, 2003, p. 501). 
senhor considera o escravo não como pessoa, mas como coisa destituída de um eu [selbstlose], e o escravo não vale ele mesmo como eu, mas o senhor é seu eu" (HEGEL, 1986b, p. 312).

Voltemos novamente ao nosso assunto propriamente dito e perguntemos: como compreender essa relação de conteúdo entre a lógica e a filosofia da religião?

De início, Hegel situa o sentido mesmo da prova da existência de Deus e examina sob que condições têm mesmo cabimento falar em prova, em se tratando desse conteúdo. Ora, a exigência de uma prova da existência de Deus também apenas se pôs no interior de uma determinada religião, o Cristianismo, no contexto de uma oposição, que ali pela primeira vez se engendrou, entre a fé e a razão, quando no peito humano se instalou a dúvida [Zweifel] acerca do divino. A própria noção de fé [Glaube] somente surge na religião cristã, pois é nela que se estabelece pela primeira vez a cisão [Zwiespalt] entre o espírito e a alma e, mais precisamente, o anseio de superação da mesma. Trata-se de um anacronismo falar em crença e fé nas religiões mais antigas, por exemplo, na grega e na egípcia. $\mathrm{Na}$ religião cristã, a fé significa precisamente o processo de interiorização da certeza de Deus, que surge como algo do qual estamos em princípio afastados, donde se depreende a necessidade da prova, que coincide com a própria elevação do espírito humano a Deus, elevação esta inscrita na natureza do nosso espírito e, portanto, apresentando-se também como necessária. E a "apresentação dessa necessidade mesma não é outra coisa senão o que nós denominamos de prova. Por isso, não temos de provar essa elevação de um modo exterior: ela se prova nela mesma; o que não significa outra coisa senão que ela é por si mesma necessária" (HEGEL, 1986b, p. 357). Assim, a estrutura da prova depende diretamente do conteúdo do que se pretende provar. "O provar foi determinado de tal forma que é apenas a consciência do próprio movimento do objeto em si mesmo" (HEGEL, 1986b, p. 357).

Essa dependência da prova e do tema a ser provado não deve aqui ser compreendida num sentido mais ingênuo de uma divisa hermenêutica de que cada objeto exige uma metodologia própria e que lhe seja adequada, como se tivéssemos que abrir uma concessão ao objeto a ser provado. Pelo contrário, o que está aqui em jogo é a própria necessidade da prova. A sugestão de que se tem de apresentar uma prova da existência de Deus depende essencialmente do modo como esse objeto ou conteúdo se apresentou e se apresenta como tal. É ele mesmo que requereu, por si, a necessidade da prova, tornou pela primeira vez possível que se pudesse "prová-lo" ou que se chegasse mesmo a essa proposta.

O que significa então, diante disso, "prova"? Na Enciclopédia das ciências Filosóficas, § 83, Hegel adverte que "provar significa na filosofia 
tanto quanto indicar [aufzeigen] o modo como o objeto por meio de si mesmo e a partir de si mesmo se transforma naquilo que ele é" (HEGEL, 1986b, p. 179-80). A prova é, sobretudo, um processo de prova, no qual não interessa apenas a conclusão como ponto culminante da prova e sim o percurso da mesma, o movimento subjetivo de elevação do espírito a Deus, que se apresenta como uma atividade de desenvolvimento concreto, como atuação e decurso. Forma e conteúdo coincidem nesse processo de apresentação da prova da existência de Deus. Não vale aqui a separação entre a fé e o saber, como se houvesse algo previamente dado (Deus), que então seria provado por argumentos racionais, os quais estariam separados da própria fé. Trata-se de compreender a prova como um assunto por si, que se apresenta com necessidade em si mesma; não há Deus de um lado e a prova de outro.

Algo análogo se passa com o domínio da lógica, que é conteúdo e forma ao mesmo tempo. A lógica não é um conjunto de preceitos formais sobre o pensamento igualmente formal, que então se aplica a um objeto, e sim ela é seu próprio objeto. Logo na "Introdução" ao Conceito geral da lógica da Ciência da Lógica, Hegel afirma que "em todas as outras ciências, o objeto a ser abordado e o método científico estão separados um do outro; bem como o conteúdo também não constitui um início absoluto, mas depende de outros conceitos e encontra-se dependente de outras matérias circundantes" (HEGEL, 1986a, p. 35). E, logo a seguir, marcando inversamente o modo como se apresenta o conteúdo específico da lógica, acrescenta que "seu objeto, o pensar ou mais determinadamente o pensamento conceitual, é essencialmente tratado no interior da mesma; o conceito do mesmo gera-se a si mesmo em seu decurso e não pode ser presumido" (HEGEL, 1986a, p. 35).

Assim, ao longo das primeiras cinco preleções sobre as provas da existência de Deus, Hegel combate a separação entre fé e razão no âmbito da filosofia da religião, defendida por Jacobi muito mais do que por Kant. A fé não se manifesta apenas ao sentimento, nem se circunscreve a uma subjetividade isolada, irônica (HEGEL, 1986c, p. 375), a um eu abstrato que se mantém apenas na relação consigo mesmo. Pelo contrário, a verdadeira fé quer se saber a si mesma, se dirige ao pensamento como âmbito que a complementa e não lhe é estranha. Ela "tem de ser ao mesmo tempo sabida como necessária, necessita adquirir uma consciência de si e da conexão de seu desenvolvimento" (HEGEL, 1986c, p. 379). E é precisamente esse movimento de tomada de consciência da fé, enquanto um processo necessário da natureza humana, real e efetivo, que Hegel considerará como sendo a prova da existência de Deus. A prova se redefine então como a tomada de consciência "do conteúdo particular no universal em si e para si, bem como do verdadeiro 
absoluto mesmo como o resultado e, assim, como a verdade última do conteúdo particular" (HEGEL, 1986c, p. 379). A tarefa de uma prova torna-se, assim, o movimento objetivo do objeto enquanto a elevação de nosso espírito a Deus.

Como pensar essa elevação? Como ela se dá? Na sexta preleção, Hegel considera que ela passa essencialmente pelo processo da consciência enquanto um movimento do para si. A elevação não é então um fenômeno, por assim dizer, antropologicamente necessário, que ocorreria naturalmente junto aos povos e aos homens em geral, como algo comum. O ponto de vista histórico não explica a questão, uma vez que a convicção [Bezeugnis], enquanto o modo como no homem ocorre a interiorização do espírito, o para si, não necessita de uma autoridade externa. É no próprio testemunho [Zeugnis] do espírito pensante que o espírito é para si pensante.

Voltemos ao início de nosso texto e perguntemos: mas, então, que relação isso tem com a lógica? A relação está no fato de aqui temos de operar uma consideração pensante [denkende Betrachtung] da existência de Deus, a qual se dá para além das categorias usuais do pensamento. Por exemplo, aplicar a Deus a categoria do ser significa reduzi-lo à noção de identidade, noção essa típica do entendimento limitado e finito que, para apreender Deus, recorre à concepção de um sujeito ao qual se atribuem vários predicados. Para além da determinação abstrata do entendimento, o conceito é "concreto em si mesmo, uma unidade que não é indeterminada, mas essencialmente determinada e, assim, apenas é como unidade de determinações. E essa unidade mesma é de tal modo ligada às suas determinações, portanto, é propriamente a unidade dela mesma e das determinações que, sem as determinações, ela nada é, sucumbe, ou mais precisamente: é ela mesma apenas rebaixada a uma unidade inverídica e carece de relação para ser algo verdadeiro e efetivo" (HEGEL, 1986c, p. 395).

No exame da prova cosmológica da existência de Deus (décima preleção), Hegel questiona a postura do saber imediato que toma a elevação a Deus como um fato [Faktum] e que desconhece o processo de mediação [Vermittlung] implicado na passagem do finito ao infinito. "É o espírito em seu âmbito mais interior, a saber, em seu pensamento, que realiza essa elevação; ela é percurso de determinações de pensamento" (HEGEL, 1986c, p. 415-16). Nesse percurso, o espírito passa por um conjunto de categorias que tem seu domicílio no campo das considerações lógicas. Esse progresso da determinação conceitual desenvolve a lógica em sua necessidade, de tal modo que cada estágio percorrido pelo conceito contém a elevação de uma categoria da finitude em sua infinitude. 
Ora, isso implica que cada estágio abriga, desde seu ponto de partida, "um conceito metafísico de Deus e, uma vez que essa elevação é apreendida em sua necessidade, contém uma prova de seu ser" (HEGEL, 1986c, p. 419). Cada passo de aprofundamento e de manifestação mais perfeita do conceito corresponde a uma das manifestações de Deus. Por conseguinte, a lógica é a "teologia metafísica que observa a evolução da ideia de Deus no éter do puro pensamento, de modo que ela propriamente apenas observa a mesma, a qual é em si e para si pura e simplesmente autônoma" (HEGEL, 1986c, p. 419).

No entanto, a prova cosmológica carece de consciência da natureza das determinações mesmas do conceito, não atenta para o fato de que as categorias da contingência e da necessidade, nos quais ela preferencialmente se apóia, são determinações exclusivas do ser, respectivamente, em sua finitude e em sua infinitude. Em sua essencialidade, porém, o ser é a realidade [Wirklichkeit] e acima desse estágio está a liberdade, mas como sendo a necessidade em sua verdade, ou melhor, o solo do conceito em que se apresentam determinações novas, como a da finalidade. Esse âmbito não é alcançado pela prova cosmológica, que se mantém nos limites da determinação da realidade, ou seja, no campo da verdade das categorias mais abstratas do ser. Como afirma Daniel Murphy, no verbete "Gottesbeweis", para Hegel, "a falha essencial da prova cosmológica reside no fato de que toma o ser finito como ponto de partida e tenta deduzir o ser infinito" (HEGEL-LEXIKON, 2006, p. 248).

\section{Referências}

JAESCHKE, W. Hegel-Handbuch. Leben, Werk, Wirkung. Stuttgart/Weimar: Metzler, 2003.

HEGEL, G.W.F. Wissenschaft der Logik. Vol. 5. In: Werke in zwanzig Bänden. Frankfurt am Main: Suhrkamp, 1986.

. Enzyklopädie der philosophischen Wissenschaften. Vol. 8. In: Werke in zwanzig Bänden. Frankfurt am Main: Suhrkamp, 1986.

. Vorlesungen über die Beweise vom Daseins Gottes. Vol. 17. In: Werke in zwanzig Bänden. Frankfurt am Main: Suhrkamp, 1986.

HEGEL-LEXIKON, hrsg. von Paul Cobben, Darmstadt, WBG, 2006.

ECKERMANN, Gespräche mit Goethe in den letzten Jahren seines Lebens. $3^{\mathrm{a}}$ ed. Zürich/München: Artemis, 1976. 